Geographia Meridionalis - Revista Eletrônica do Programa de Pós-Graduação em Geografia da Universidade Federal de Pelotas

http://periodicos.ufpel.edu.br/ojs2/index.php/Geographis/index ISSN 2446-9165

Recebido em:28/09/2017

Revisões Requeridas em: 10/11/2017 Aceito em:20/11/2017

\title{
LEVANTAMENTO DE SOLOS NO BRASIL: MÉTODOS, PRÁTICAS E DIFICULDADES.
}

\author{
Cláudia Werner Flach \\ Universidade Federal de Pelotas \\ Mestra e licenciada em Geografia \\ cwflach@gmail.com \\ Edvania Aparecida Corrêa \\ Universidade Federal de Pelotas \\ Professora Doutora do Departamento de Geografia \\ edvania.correa86@gmail.com
}

\section{1 - Introdução}

A execução de levantamentos de solos no Brasil não é recente. Entretanto, apesar dos inúmeros trabalhos realizados e publicados até o presente momento, ainda há carência de informações, especialmente em relação a informações em escala de maior detalhe.

Por definição, um levantamento pedológico é um prognóstico da distribuição dos solos enquanto corpos naturais. Um levantamento identifica os solos, além de prever e delinear suas áreas nos mapas através de classes (EMBRAPA, 1995). Para Lepsch (2011), os levantamentos de solos apresentam a distribuição espacial das classes de solos, bem como sua descrição e interpretação, fornecendo informações essenciais para a tomada de decisões em áreas agrícolas e urbanas.

Desta forma, as informações provenientes do levantamento pedológico são base de dados para projetos e planejamento de uso, manejo e conservação de solos, subsidiando a avaliação do potencial e das limitações de uma área (EMBRAPA, 2016, IBGE, 2015).

Os trabalhos realizados até o momento foram importantes para o conhecimento dos solos brasileiros. No entanto, em geral, são insuficientes para atender às demandas de planejamento de uso terra e preservação ambiental, em função da escala e do nível de detalhamento das informações (EMBRAPA, 2016; WEBER et al., 2006).

Considerando a importância e a carência de levantamento de solo de maior detalhe no território brasileiro bem como a proposição de novas metodologias envolvendo o uso de 
Geotecnologias, o objetivo da presente nota é destacar os principais métodos e técnicas utilizados no mapeamento de solos e as dificuldades existentes na realização dos mapeamentos de maior detalhe no território brasileiro. Para tanto, foi realizada revisão bibliográfica acerca do tema, envolvendo pesquisas em bases qualificadas e em diversas áreas científicas. Como termos de pesquisa, foram utilizados "levantamento/mapeamento de solo, histórico dos levantamentos, técnicas de levantamento, dentre outros"

\section{2 - Levantamento de Solos no Brasil: histórico, importância, dificuldades e inciativas}

No Brasil, os levantamentos de solos iniciaram-se apenas na década de 1940 com a elaboração do Esboço Agrogeológico do Estado de São Paulo, em 1943. Em 1947, foi criada a Comissão de Solos do Serviço Nacional de Pesquisas Agronômicas (Ministério da Agricultura), considerada como um marco nos levantamentos de solo a nível nacional (CAMARGO, et al., 2010; CARVALHO et al., 2013).

Esses primeiros levantamentos de solos eram realizados através da prospecção por caminhamento livre, sem um método estabelecido. Em geral, a base para o levantamento de solos era constituída por mapas geológicos e cartas planialtimétricas. Assim, os delineamentos dos diferentes tipos de solos, reconhecidos por observações em campo, eram dispostos em papel vegetal sobre mapas/cartas base (CARVALHO et al., 2013).

A ampliação da agricultura no país levou a criação do Programa de Levantamento de Reconhecimento dos Solos Brasileiros (1953), com estudos iniciais no Rio de Janeiro e Distrito Federal. Nesse período, os pesquisadores receberam importante apoio e assistência técnica da FAO (Food and Agriculture Organization of the United Nations), o que tornou o país palco para os estudos em solos tropicais (CARVALHO et al., 2013; LEPSCH, 2013).

É a partir dos levantamentos realizados no Rio de Janeiro e no Distrito Federal (1958) e em São Paulo (1960) que começaram a ser utilizadas combinações de fatores de formação do solo segundo critérios taxonômicos, impulsionando o reconhecimento dos solos em classes. Nos anos de 1960 passam a serem utilizadas fotografias aéreas combinadas com o uso de estereoscópios e mesas de luz. Esses equipamentos eram fundamentais para delinear as diferentes unidades de solo, permitindo ao profissional estabelecer relações 
entre os solos e as diferentes feições da paisagem, além de determinar a distribuição espacial e os limites entre unidades de solos no mapa final (CARVALHO et al., 2013).

Durante as décadas de 60, 70 e 80, os trabalhos iniciados pela Comissão de Solos do Serviço Nacional de Pesquisas Agronômicas tiveram continuidade por meio do Serviço Nacional de Levantamento e Conservação de Solos da Embrapa (SNLCS). Esses trabalhos proporcionaram levantamentos de solos em nove Estados brasileiros, além do Mapa Esquemático dos Solos (regiões Norte, Meio-Norte e Centro Oeste do Brasil) e do Mapa de Solos do Brasil (escala 1:5.000.000) (EMBRAPA, 2016; RAMOS, 2003).

Tendo em vista a necessidade de informações de solos, a grande extensão territorial e a carência de recursos, entre 1970 e 1985, foram executados mapas generalizados de solos que permitiram um amplo inventário do meio físico e biótico de grande parte do país (EMBRAPA, 2016). Neste período, destacam-se as iniciativas do projeto RADAMBRASIL, responsável pela execução de levantamentos de solos na escala 1:1.000.000 de 43 folhas do sistema de projeção UTM. A criação do projeto também estimulou o uso de técnicas de fotointerpretação em imagens de sensores remotos permitindo os levantamentos em todo território nacional (CARVALHO et al., 2015; EMBRAPA, 2016; LEPSCH, 2013; RAMOS, 2003).

Já na década de 1995 foi publicado pela Embrapa o Manual de Procedimentos Normativos de Levantamentos Pedológicos. Esse material buscava a padronização dos mapeamentos, apresentando normas, critérios e métodos de levantamentos pedológicos (CARVALHO et al., 2013, EMBRAPA, 1995). A necessidade de estabelecer um sistema de classificação nacional que consolidasse a sistematização taxonômica dos solos serviu de arcabouço para a elaboração do Sistema Brasileiro de Classificação de Solos, publicado em 1999, pela EMBRAPA. Esse sistema permitiu uma padronização na classificação dos solos a nível nacional, uma vez que abrangeu as peculiaridades e a grande diversidade dos solos brasileiros (CARVALHO et al., 2013; EMBRAPA, 2013).

De acordo com Santos et al. (2013), todo o território nacional possui levantamentos esquemáticos de solos com escala entre 1:1.000.000 e 1:5.000.000. Os levantamentos de reconhecimento de solos de baixa intensidade (escala 1:250.000 a 1:750.000) ocorrem em aproximadamente $84,2 \%$ do território nacional, os de média intensidade (escala 1:100.000 a 1:250.000) em apenas 8,4\% do território e os levantamentos de alta 
intensidade (escala 1:50.000 a 1:100.000) em 1,71\% do território. Ou seja, foram realizados poucos levantamentos de solos em escala de maior detalhe, essenciais para o direcionamento de atividades de uso e conservação da terra em âmbito local (EMBRAPA, 2016; WEBER et al., 2006).

Por outro lado, o país se destaca nos estudos de solos tropicais, com grande volume de informações pedológicas por meio de levantamentos de solos de grande abrangência. Porém, a disponibilização das informações é pouco eficiente (grande volume, complexidade e pouca normatização dos dados), limitando a utilização (BENEDETI et al., 2008). Assim, em 2008, por iniciativa do Departamento de Ciência dos Solos (Escola Superior de Agricultura Luiz de Queiroz - ESALQ/SP), foi estruturado um banco de dados de solos, a fim de disponibilizar informações padronizadas. Esse banco de dados conta com 10.950 horizontes, de 5.479 perfis de solo e 57 colunas de variáveis independentes (ano do levantamento, classificação original, declividade, drenagem, profundidade do horizonte, cor úmida, granulometria, teor de óxidos, dentre outras) (BENEDETTI et al., 2008; BENEDETTI et al., 2011).

Apesar do considerável aumento das pesquisas relacionadas aos solos no Brasil, o início do século XXI foi marcado pelo declínio das pesquisas, contribuindo com a carência de informações em escala adequada para tomada de decisão (CARVALHO et al., 2015). Essa carência se deve aos problemas orçamentários e financeiros e à indisponibilidade de bases cartográficas confiáveis para a execução dos levantamentos (WEBER et al., 2006; RAMOS, 2003), além da dificuldade de acesso em muitas áreas e a resistência de pesquisadores em adotar um método mais moderno de levantamento (CARVALHO et al., 2013). Outro fator que contribuiu para essa redução foi a descontinuidade de programas governamentais e a extinção de algumas agências e projetos (CARVALHO et al., 2015).

Como o atual nível de mapeamento de solos não é suficiente para embasar o planejamento do uso da terra e das ações de conservação e recuperação do solo e da água em âmbito local, atualmente é necessário adquirir informações de sensoriamento remoto, geotecnologias, GPS e programas computacionais para o avanço da cartografia de solos (CARVALHO et al, 2013; CARVALHO et al., 2015). Nesse sentido, diferentes métodos vêm sendo testados e utilizados, a fim de produzir mapas pedológicos detalhados e com 
baixo custo, visto o prévio levantamento ser realizado indiretamente por técnicas de Sensoriamento Remoto.

Dentre as novas estratégias, destaca-se a Rede Brasileira de Pesquisa em Mapeamento Digital de Solos (RedeMDS), criada em 2011, sob a coordenação da EMBRAPA Solos. Os trabalhos desse grupo são baseados em métodos matemáticos, numéricos e estatísticos (redes neurais, regressões logísticas múltiplas, árvore de decisão, lógica fuzzy, krigagem), que permitem estabelecer relações entre solos e variáveis ambientais (CARVALHO et al., 2013). Outro destaque é o Programa Nacional de Solos do Brasil (PronaSolos), criado em 2015, com o objetivo de retomar a realização dos levantamentos pedológicos, além de estabelecer uma base de dados integrada (com informações anteriormente produzidas, bem como as que vierem a ser produzidas) (EMBRAPA, 2016).

Todas essas iniciativas reforçam que os levantamentos de solos são instrumentos imprescindíveis para o planejamento e gerenciamento dos recursos naturais (BENEDETTI et al., 2011; CARVALHO et al., 2013; LEPSCH, 2013). Ou seja, são fundamentais para a proposição de políticas territoriais, para a criação de legislação específica e para a construção de instrumentos de caráter jurídico-administrativo a fim de formular diretrizes de preservação, recuperação, conservação e desenvolvimento (CARVALHO et al., 2013).

\section{3 - Métodos e técnicas utilizados nos mapeamentos de solos: vantagens e limitações}

É crescente a necessidade de executar mapas com menor custo e maior rapidez. Nesse cenário, as técnicas de geoprocessamento tornaram-se aliadas nos levantamentos de solos, subsidiando o planejamento territorial e os inventários ambientais (NOLASCOCARVALHO et al., 2009; CARVALHO et al., 2013) Essas técnicas emergiram como alternativas para os mapeamentos, permitindo a integração e a modelagem de grandes quantidades de dados e informações em diferentes formatos (CARVALHO et al., 2015).

O desenvolvimento de projetos em ambiente SIG permite a combinação de dados espaciais, possibilitando a descrição e análise de interações, de modo a subsidiar a definição de classes, unidades ou sítios de interesse. Entretanto, é fundamental que trabalhos em SIG envolvendo levantamento pedológico sejam precedidos pela confecção do mapa preliminar com o delineamento de unidades e a sobreposição de dados 
ambientais, além da incorporação das informações obtidas a campo (NOLASCOCARVALHO et al., 2009).

Desta forma, são apresentados três métodos e técnicas utilizados na execução de levantamentos pedológicos: mapeamento convencional de solos; mapeamento digital de solos; e mapeamento de solos por determinação espectral.

\section{Mapeamento Convencional de Solos}

O levantamento pedológico tradicional, o qual é amplamente difundido e ainda muito utilizado, fundamenta-se no conceito de solo enquanto corpo natural com características próprias, completo e indivisível. Esse método tem como base a análise fisiográfica da paisagem e a interpretação de fotografias aéreas ou imagens de satélite. Descreve as características do solo, classificando-os de acordo com um sistema taxonômico e estabelecendo limites entre classes definidas no mapa. Tal método pressupõe que os fatores de formação controlam a distribuição dos diferentes tipos de solos na paisagem (MENDONÇA-SANTOS; SANTOS, 2003).

Inicialmente são coletadas e organizadas informações sobre a área de estudo para compor a base cartográfica. A intensidade das observações a campo deve permitir a identificação de possíveis unidades a serem mapeadas. Procede-se a coleta de amostras de solos para análises laboratoriais (para aferição das características químicas, físicas, mineralógicas e físico-hídricas de cada unidade de mapeamento). Os profissionais responsáveis pelo levantamento interpretam características locais de topografia e vegetação, utilizando essas informações como indícios de combinações dos fatores de formação dos solos, possibilitando inferir os limites entre classes e propriedades dos solos (LIMA et al., 2013).

Dentre as limitações deste método, destaca-se que o levantamento convencional é uma atividade onerosa, demandando muito tempo e muitos deslocamentos ao campo, o que resulta em custos elevados (LIMA et al., 2013). Outra limitação se deve ao fato de que esse método não considera a dependência espacial entre as unidades de mapeamento, ou seja, assume-se que as classes de solos possuem limites abruptos (MENDONÇASANTOS; SANTOS, 2003). 


\section{Mapeamento Digital de Solos}

A crescente preocupação ambiental e o desenvolvimento da agricultura de precisão passaram a demandar novos levantamentos de solos, sendo fundamental o uso de ferramentas que auxiliem na maior eficiência da delimitação das unidades de solos (LIMA et al., 2013). Nesse sentido, a partir de 2006 começaram a ser produzidos levantamentos de solo através de Mapeamento Digital de Solos (MDS), visando aumentar a viabilidade da execução dos levantamentos através do uso de Geotecnologias (CARVALHO et al., 2015; MENDONÇA-SANTOS; SANTOS, 2003, TEN CATEN, et al., 2012).

Esse método é pautado na criação e alimentação de sistemas espaciais de informações de solos, através de modelos numéricos para inferir variações espaciais dos tipos de solos ou de suas propriedades. É um método que adota a modelagem quantitativa dos solos, com o uso de um conjunto de técnicas denominadas de pedometria (MENDONÇA-SANTOS; SANTOS, 2003, TEN CATEN, et al., 2012).

Assim como o método convencional, também é elaborada a base cartográfica da área de estudo e o esboço fotopedológico, que permitem determinar os locais de amostragem a campo (LIMA et al., 2013). Nos pontos pré-determinados, são coletadas amostras de solo através de tradagens em diferentes profundidades, georeferenciando-as com um receptor GPS de precisão (NANNI et al., 2015). Com base nessas amostras, são realizadas análises laboratoriais químicas e granulométricas (DEMATTÊ et al., 2004).

Baseado nas informações de campo e nas análises de laboratório são estabelecidas as relações entre os pontos amostrais e as variáveis preditoras. É gerado o mapa digital, que deve ser verificado a campo e testado para identificação do erro associado. Uma das vantagens do MDS é a possibilidade de utilizar modelagem para extrapolar os dados para áreas com características ambientais semelhantes (LIMA et al., 2013). Dentre as funções matemáticas utilizadas, destacam-se as regressões logísticas, a mineração de dados por árvore de decisão, as redes neurais e a lógica fuzzy (MENDONÇA-SANTOS; SANTOS, 2003, NOLASCO-CARVALHO et al., 2009, TEN CATEN et al., 2012).

Para Ten Caten et al. (2012), é fundamental o treinamento de pessoas aptas a implementar projetos de mapeamentos digitais de solos. Além disso, é necessária a elaboração de levantamentos convencionais, pois estes produzem informações capazes de treinar 
modelos e predizer classes e propriedades de solos em áreas não mapeadas. Ou seja, essas diferentes abordagens se complementam, otimizando recursos humanos e financeiros.

\section{Mapeamento de Solos por Determinação Espectral}

O mapeamento de solos por determinação espectral, uma das estratégias mais recentes no levantamento de solos, torna tal prática mais rápida e menos onerosa. Essa técnica baseiase nas diferenças de absorção e reflexão da energia eletromagnética dos diferentes tipos de solos (influenciadas pelos atributos químicos, físicos e mineralógicos). Considerando que a curva de reflectância espectral é única para cada amostra de solo, a avaliação espectral permite quantificar os atributos do solo (DEMATTÊ et al., 2004).

Para a aquisição de informações espectrais são utilizadas técnicas de sensoriamento remoto em todos os níveis de aquisição de dados. Esses dados podem ser adquiridos no nível orbital (através de sensores multiespectrais, hiperespectrais e de alta resolução espacial), no nível aéreo (fotografias aéreas), além de informações obtidas por sensores terrestres e em laboratório (DEMATTÊ et al., 2004).

Para avaliar a variação do componente espectral das classes de solos, são utilizadas diferentes bandas do visível e do infravermelho, através de composição colorida falsa cor, que permite a delimitação preliminar das unidades de mapeamento do solo. A análise quantitativa das imagens digitais deve ser feita com os dados de reflectância ajustados aos modelos atmosféricos, permitindo a conversão dos números digitais em valores de reflectância real. Em pontos pré-selecionados em áreas de solos exposto, são coletados os dados espectrais com o auxílio de programa específico. A localização é inserida num banco de dados responsável pela extração dos valores de intensidade de reflectância das bandas (DEMATTÊ et al., 2005).

Outra forma de obter a determinação espectral dos solos é através de espectrorradiometria. Essa técnica permite a aquisição de informações espectrais detalhadas das características e atributos do solo. Para tanto, são coletadas amostras de solos a campo, que são preparadas em laboratório. A interpretação das curvas espectrais permite a identificação de picos de absorção e seus valores, bem como de feições específicas dos constituintes pedológicos com maior influência na resposta espectral do solo (SANTOS, FRANCA-ROCHA, 2015). 


\section{Averiguação dos Levantamentos}

Independente da técnica utilizada é imprescindível verificar as informações geradas no levantamento de solos. Assim, se o usuário do mapa/levantamento conhece a qualidade das informações representadas, este pode decidir se o material é aplicável ao uso pretendido (LIMA et al., 2013).

Quanto aos responsáveis pela produção dos mapeamentos, é fundamental a averiguação das informações, que pode ser realizada por meio de matrizes de erro e confusão. A preparação da matriz de erro e confusão permite identificar o erro global da classificação de cada classe de solo por meio da tabulação cruzada entre duas informações (LIMA et al., 2013). Dessa forma é possível verificar a qualidade obtida, seja por meio da correlação de informações dos dados de referência (compreendidos como verdadeiros) com os dados classificados ou através da análise das amostras de treinamento juntamente com os dados classificados (quando não existem dados de referência) (PRINA; TRENTIN, 2015).

A matriz de erro e confusão permite calcular o índice kappa, o índice de exatidão global e o índice de concordância além da precisão de classe individual, precisão de produtor e precisão de usuário (FIGUEIREDO; VIEIRA, 2007). Tais índices são fundamentais para avaliar a acurácia das unidades de mapeamento tendo como base os dados coletados em campo (PRINA; TRENTIN, 2015).

\section{4 - Considerações Finais}

Com base nas informações apresentadas, destaca-se a dificuldade para a realização de levantamentos pedológicos em escala de detalhe, uma vez que estes dependem não somente da coleta de informações a campo, mas também de uma base de dados confiável e adequada para a escala de trabalho. Em função da grande extensão territorial do país, a promoção de pesquisas e levantamentos de solos por parte de órgãos, instituições e agências governamentais figura como a melhor alternativa para o avanço na produção de informações detalhadas para todo o território nacional. Ou seja, é fundamental investimentos para a ampliação das pesquisas relacionadas aos solos, não apenas com foco no levantamento e classificação para expansão das áreas agrícolas, mas também com foco para a proposição de medidas de conservação dos solos e recuperação de áreas degradadas. 


\section{REFERÊNCIAS}

BENEDETTI, M.M; SPAROVEK, G.; COOPER, M.; CURI, N.; CARVALHO FILHO, A.de. Representatividade e potencial de utilização de um banco de dados de solos do Brasil. R. Bras. Ci. Solo, v. 32, n.6, p. 2591-2600, 2008.

BENEDETTI, M.M.; CURI, N.; SPAROVEK, G.; CARVALHO FILHO, A.; SILVA, S.H.G. Updated Brazilian's Georeferenced Soil Database - An Improvement for International Scientific Information Exchanging. In: GUNGOR, E.B.O. (Org) Principles, Application and Assessment in Soil Science. Riijeka: InTech - Open Access Publisher, 2011, v.1, p. 309-332.

CAMARGO, F.A.de O.; ALVAREZ, V.H.; BAVEYE, P.C. Brazilian soil science: from its inception to the future, and beyond. R. Bras. Ci. Solo, v.34, p. 589-599, 2010.

CARVALHO, C.C.N. de.; NUNES, F.C.; ANTUNES, M.A.H. Histórico do levantamento de Solos no Brasil da industrialização brasileira à era da informação. Revista Brasileira de Cartografia, n.65/5, p. 997-1013, 2013.

CARVALHO, C.C.N. de.; NUNES, F.C.; ANTUNES, M.A.H., NOLASCO, M.C. Soil Surveys in Brazil and Perspectives in Soil Digital Mapping. Soil Horizons, v.56, n.6, p. $1-10,2015$.

DEMATTÊ, J.A.M.; GENÚ, A.M.; FIORIO, P.R.; ORTIZ，J.L.; MAZZA，J.A.; LEONARDO, H.C.L. Comparação entre mapas de solos obtidos por sensoriamento remoto espectral e pelo método convencional. Pesq. agropec. bras., v.39, n.12, p.12191229, 2004.

DEMATTÊ, J.A.M.; MORETI, D.; VASCONCELOS, A.C.F.de, GENÚ, A.M. Uso de imagens de satélite na discriminação de solos desenvolvidos de basalto e arenito na região de Paraguaçu Paulista. Pesq. agropec. bras., v.40, n.7, p.697-706, 2005.

EMBRAPA. Empresa Brasileira de Pesquisa Agropecuária. Procedimentos normativos para levantamentos pedológicos. Brasília: EMBRAPA, 1995. Disponível em: https://www.embrapa.br/solos/busca-de-publicacoes/-/publicacao/330133/procedimentos-normativos-de-levantamentos-pedologicos. Acesso em: agosto de 2017.

Embrapa 1999 (publicação do Sistema Brasileiro de Classificação de Solos) - pág 3

EMBRAPA. Empresa Brasileira de Pesquisa Agropecuária. Sistema Brasileiro de Classificação de Solos. 3.ed. Brasília: Embrapa, 2013.

EMBRAPA. Empresa Brasileira de Pesquisa Agropecuária. Programa Nacional de Solos do Brasil (PronaSolos). Rio de Janeiro: Embrapa Solos, 2016. Disponível em: https://www.embrapa.br/busca-de-publicacoes/-/publicacao/1054924/programanacional-de-solos-do-brasil-pronasolos. Acesso em: julho de 2017.

FIGUEIREDO, G.C.; VIEIRA, C.A.O. Estudo do comportamento dos índices de Exatidão Global, Kappa e Tau, comumente usados para avaliar a classificação de 
imagens do sensoriamento remoto. In: XIII SIMPÓSIO BRASILEIRO DE SENSORIAMENTO REMOTO, 2007, Florianópolis/SC.INPE. p.5755-5762.

IBGE. Instituto Brasileiro de Geografia e Estatística. Manual técnico de Pedologia. 3ed. Rio de Janeiro: IBGE, 2015. Disponível em: https://biblioteca.ibge.gov.br/visualiza cao/livros/liv24989.pdf. Acesso em: maio de 2017.

LEPSCH, I. F. 19 lições de Pedologia. São Paulo: Oficina de Textos, 2011.

LEPSCH, I.F. Status of Soil Surveys and Demand for Soil Series Descriptions in Brazil. Soil Horizons, v.54, p. 1-5, 2013.

LIMA, L.A.de S.; NEUMANN, M.R.B.; REATTO, A.; ROIG, H.L. Mapeamento de Solos do Tradicional ao Digital. Planaltina: Embrapa Cerrados, 2013. Disponível em: https://www.embrapa.br/busca-de-publicacoes/-/publicacao/1005933/mapeamento-desolos-do-tradicional-ao-digital. Acesso em: maio de 2017.

MENDONÇA-SANTOS, M. de L.; SANTOS, H.G. dos. Mapeamento Digital de Classes e Atributos de Solos: métodos, paradigmas e novas técnicas. Rio de Janeiro: Embrapa Solos, 2003. Disponível em: https://www.embrapa.br/busca-de-publicacoes//publicacao/338308/mapeamento-digital-de-classes-e-atributos-de-solos-metodosparadigmas-e-novas-tecnicas. Acesso em: junho de 2017.

NANNI, M.R.; DEMATTÊ, J.A.M.; SILVA JUNIOR, C.A.da; ROMAGNONI, F.; SILVA, A.A.da; CEZAR, E.; GASPAROTO, A.de C.; CAMPOS, R.M.; SACIOTO, M.; CHICATI, M.L.; OLIVEIRA, R.B.de. Comparação entre mapas de solos obtidos por métodos tradicionais e por sensores remotos orbital e terrestre. In: XVII SIMPÓSIO BRASILEIRO DE SENSORIAMENTO REMOTO, 2015, João Pessoa/PB. INPE. p.5400-5407.

NOLASCO-CARVALHO, C.C.; FRANCA-ROCHA, W.; UCHA, J.M. Mapa digital de solos: Uma proposta metodológica usando inferência fuzzy. Revista Brasileira de Engenharia Agrícola e Ambiental, v.13, n.1, p.46-55, 2009.

PRINA, B.Z.; TRENTIN, R. GMC: Geração de Matriz de Confusão a partir de uma classificação digital de imagem do ArcGIS®. In: XVII SIMPÓSIO BRASILEIRO DE SENSORIAMENTO REMOTO, 2015, João Pessoa/PB INPE. p.0131-0139.

RAMOS D. P. Desafios da Pedologia Brasileira frente ao novo milênio. In: XXIX CONGRESSO BRASILEIRO DE CIÊNCIA DO SOLO, 2003 Ribeirão Preto, SP. Viçosa: Sociedade Brasileira de Ciência do Solo,. p.01-09.

SANTOS, S.M.B. dos; FRANCA-ROCHA, W.de J.S. da. Biblioteca espectral de solos em uma área no município de Mucugê - Ba. In: XVII SIMPÓSIO BRASILEIRO DE SENSORIAMENTO REMOTO, 2015, João Pessoa/PB INPE. p.6298-6304.

SANTOS, H.G.dos; AGLIO, M.L.D.; DART, R.de O.; BREFFIN, M.de L.M.S.; SOUZA, J.S.de; MENDONÇA, L.R. Distribuição Espacial dos Níveis de Levantamento de Solos no Brasil. In: XXXIV CONGRESSO BRASILEIRO DE CIÊNCIA DO SOLO. 
2013, Florianópolis. Ciência do Solo: Para que e para quem? Programa \& Resumos. Editora: Epagri e SBCS. p.1 - 4.

TEN CATEN, A.; DALMOLIN, R.S. D.; MENDONÇA-SANTOS, M.L.; GIASSON, E. Mapeamento digital de classes de solos: características da abordagem brasileira. Ciência Rural, v.42, n.11, p. 1989-1997, 2012.

WEBER, E.; HASENACK, H.; FLORES, C.A. Geoprocessamento no apoio ao mapeamento de solos. In: FLORES, C.A. (Org), POTTER, R.O., FASOLO, P.J.; HASENACK, H.; WEBER, E. Levantamento semi-detalhado de solos: região da campanha - Folha Palomas, Estado do Rio Grande do Sul. Porto Alegre: Editora da UFRGS, 2006. 